\title{
Pengimplementasian SMART Patrol Terhadap Aktivitas Illlegal (Pembalakan dan Perambahan) di Kawasan Konservasi Suaka Margasatwa Rawa Singkil (Implementation of SMART Patrol on Illegal Activities Logging and Acroachment in the conservation area of Singkil Swamp Wildlife Reserve )
}

\author{
Radiana Sofyan $^{1}$, Iqbar $^{1}$, Ryan Moulana $^{1 *}$ \\ Program Studi Kehutanan PSDKU UNSYIAH Gayo Lues \\ Universitas Syiah Kuala \\ *Corresponding author: ryanmoulana@unsyiah.ac.id
}

\begin{abstract}
Abstrak. Suaka Margasatwa Rawa Singkil adalah kawasan Konservasi yang ada di Pulau Sumatera Provinsi Aceh dan merupakan habitat bagi orangutan sumatera. Tujuan penelitian ini untuk mengetahui pengimplementasian SMART Patrol oleh resor Rundeng terhadap beberapa aktivitas illegal. Parameter pada penelitian ini adalah pembalakan liar dan perambahan. Pengumpulan data dilakukan dengan teknik survei, pengambilan data dilakukan dengan mengambil data langsung di lapangan pada bulan Mei, Juni, dan Juli 2019 dan menggunakan data SMART Patrol dari tahun 2016, menggunakan jurnal dan sumber informasi lain yang mendukung penelitian serta menganalisis semua data secara deskriptif. Hasil yang diperoleh dari penelitin ini adalah kegiatan SMART Patrol dapat mendata aktifitas illegal di lapangan. SMART menyimpan dan menyajikan data kawasan SM. Rawa Singki. Kedua data yang diamati pada penelitian ini menunjukkan penurunan dari tahun 2016 hingga 2019. Data SMART Patrol digunakan sebagai data base untuk pengelolaan kawasan SM. Rawa Singkil. Pengimplementasian SMART Patrol yang dilakukan di lapangan digunakan untuk pengamanan dan pengelolaan kawasan SM. Rawa Singkil beserta keanekaragaman hayati yang ada di dalamnya. SMART Patrol juga didukung dengan berbagai upaya dan kegiatan lain yaitu dengan sosialisasi dan penyuluhan serta melakukan kerjasama dengan berbagai pihak termasuk dengan menerapkan hukum dan sanksi.
\end{abstract}

Kata Kunci: Suaka Margasatwa Rawa Singkil, SMART Patrol, Aktivitas illegal, Orangutan sumatera.

\begin{abstract}
Singkil Swamp Wildlife Reserve is a conservation area on the island of Sumatera in Aceh Province an is a habitat for sumatran orangutan. The purpose of the study was to determine the area's security activities by the Rundeng resort bases SMART Patrol. The parameters in this study are illegal logging and accroachment. Data collection is done by survey technique, data analysis was performed by taking data directly in the field on Mei, Juni and Juli 2019 and using data from 2016, using journal and other source of information that support and analyze all data descriptively. The result obtained from this study are SMART Patrol activities that can record illegal activities in the field. SMART stores and presents data on the Singkil Swamp Wildlife Reserve area. Both data observed in this study show a decrease from 2016 to 2019. SMART Patrol data can be used as a data base for the management of the Singkil Swamp Wildlife Reserve. Implementation of SMART Patrol conducted in the field for the security and management of the Rawa Singkil Swamp Wildlife Reserve area along with bodiversity in it is supported by various efforts and ather unitiatives outside the area, namely through sosialization and counseling and collaborating with various parties including by implementation laws and sanctions.
\end{abstract}

Keywords: Singkil Swamp Wildlife sanctuary, Sumatran orangutan, SMART Patrol, Illegal activities.

\section{PENDAHULUAN}

Suaka Margasatwa Rawa Singkil (SM. Rawa Singkil) merupakan suatu kawasan konservasi yang berada di Pulau Sumatera Provinsi Aceh. Kawasan SM. Rawa Singkil mencakup beberapa Kabupaten/Kota di Provinsi Aceh, yaitu di Kabupaten Aceh Selatan (Resor KW 16 Trumon), Kota Subulussalam (Resor KW 17 Rundeng) dan Kabupaten Aceh Singkil (Resor KW 18 Singkil) dengan luas 81.802,22 ha. Dalam penelitian yang telah dilakukan oleh Wich et al., (2016), kepadatan populasi orangutan di kawasan SM. 
Rawa Singkil mencapai 1,75 ind $/ \mathrm{km}^{2}$ dan merupakan habitat terpadat populasi orangutan sumatera ke 2 di Aceh setelah Suaq Belimbing (Rahmadi, 2019).

Kawasan SM. Rawa Singkil sangat banyak mendapat ancaman yang dapat merusak hutan dan segala keanekaragaman hayati yang ada di dalamnya. Berbagai ancaman tersebut diharapkan dapat diperkecil dan dicegah melalui kegiatan patroli pengamanan kawasan SM. Rawa Singkil secara rutin yang dilaksanakan oleh tim gabungan yang terdiri dari berbagai unsur yaitu: Balai Konservasi Sumber Daya Alam (BKSDA) Aceh Seksi Konsevasi Wilayah (SKW) II Subulussalam bersama mitra dari unsur Lembaga Swadaya Masyarakat (LSM) yaitu Wildlife Conservation Society-Indonesia Program (WCS-IP), United States Agency for International Develpoment (USAID), Kepolisian, Tentara, beserta kelompok masyarakat yang mempunyai surat kerja sebagai Masyarakat Mitra Polisi Hutan (MMP). Kegiatan yang berhubungan dengan kawasan SM. Rawa Singkil tersebut di bawah tanggung jawab KPHK (Kesatuan Pengelolaan Hutan Kawasan Konservasi) Rawa Singkil. Patroli tersebut berbasis teknologi yang di sebut SMART (Spatial Monitoring and Repotring Tools) atau rangkaian untuk kegiatan tersebut dinamakan dengan SMART Patrol.

Aplikasi SMART adalah alat atau tool yang memiliki kemampuan untuk merencanakan, mendokumentasikan, menganalisis, melaporkan, serta mengelola data keanekaragaman hayati, data patroli atau data ancaman, dan tindakan intervensi manajemen di lapangan. SMART memiliki 4 komponen pengambilan data utama, yakni data spasial, lokasi, waktu dan tanggal patroli (Puspita, 2015).

Dengan adanya aplikasi terbaru yang ada, kini SMART Patrol telah banyak digunakan dalam segala upaya perlindungan kawasan-kawasan konservasi di Indonesia. Oleh karena itu perlu adanya kajian tentang pengimplementasian SMART Patrol terhadap aktifitas illegal di kawasan konservasi SM. Rawa Singkil oleh resor Rundeng.

\section{METODE PENELITIAN}

\section{Tempat dan Waktu Penelitian}

Penelitian dilakukan di kawasan konservasi Suaka Margasatwa Rawa Singkil resor Rundeng Kota Subulussalam dan dilakukan selama 3 bulan yaitu pada bulan Mei, Juni, dan Juli tahun 2019.

\section{Metode Penelitian}

Penelitian ini menggunakan metode penelitian dengan teknik survei dengan melakukan patroli langsung di lapangan. Data yang dikumpulkan di lapangan adalah data aktivitas illegal di kawasan yaitu pembalakan dan perambahan. Data yang diperoleh kemudian dientri ke SMART.

Dengan menggunakan data hasil patroli selama penelitian dan ditambah dengan data hasil patroli tahun 2016, 2017, 2018 hingga 2019 yang dilakukan oleh resor Rundeng BKSDA Aceh SKW II Subulussalam menggunakan aplikasi SMART terhadap aktivitas illegal tersebut di SM. Rawa Singkil. Semua data tersebut lalu dianalisis secara deskriptif.

\section{Jenis dan Sumber Data}

1. Data primer diperoleh dari 3 bulan penelitian di lapangan dengan melakukan SMART Patrol untuk mengumpulkan parameter aktivitas illegal terhadap orangutan sumatera di kawasan SM. Rawa Singkil. 
2. Data sekunder adalah data SMART Patrol dari tahun 2016 hingga 2019 dan dengan mencari literatur, artikel dan jurnal serta sumber informasi lain yang dapat mendukung informasi yang berhubungan dengan objek penelitian.

\section{Analisis Data}

Setelah mengumpulan data, data dientri di perangkat SMART. Data lainnya yang digunakan adalah data sekunder, yaitu data hasil SMART Patrol sebelumnya yang telah dilakukan oleh tim SMART Patrol BKSDA Aceh SKW II Subulussalam resor Rundeng dari tahun 2016. Data yang diperoleh dianalisis dan dituliskan menjadi hasil penelitian. Data yang diperoleh ditampilkan menjadi grafik dan dianalisis secara deskriptif.

\section{HASIL DAN PEMBAHASAN}

\section{Perencanaan dan Kegiatan SMART Patrol}

SMART Patrol dilakukan 14 hari dalam 1 bulan dan terbagi menjadi 2 trip, dengan masing-masing trip biasanya adalah 7 hari atau lebih, tergantung kondisi di lapangan. Perencanaan dan tujuan patroli disusun sebelum kegiatan patroli dilaksanakan. Perencanaan meliputi jumlah dan komposisi tim, sasaran tempat dan sasaran target patroli, jalur patroli, dan transportasi.

\section{Aktifitas illegal}

Penelitian yang dilakukan pada bulan Mei, Juni dan Juli ditemukan adanya aktifitas illegal pembalakan liar namun untuk jerat satwa tidak ditemukan pada pengamatan di lapangan. Lokasi pembalakan tersebut ada yang terdapat di dalam kawasan SM. Rawa Singkil dan ada yang di Areal Penggunaan Lain (APL). Pada beberapa lokasi, ditemukan adanya pelaku beserta barang buktu kayu olahan dan alat kerja.

\section{Pembalakan Liar (Illegal Logging)}

Kasus pembalakan liar ditemukan pada patroli di bulan Juli 2019. Terdapat 11 kasus pembalakan liar, 8 lokasi di dalam kawasan Sm. Rawa Singkil dan 3 lokasi berada di APL. Lokasi yang ditemukan beserta pelaku dan barang bukti yaitu 2 di dalam kawasan dan 1 lokasi di APL. Dalam kegiatan patroli yang menemukan pelaku di lapangan, terdapat beberapa tahapan yang dilakukan oleh tim untuk mengamankan para pelaku, yakni:

1. Mendata identitas.

2. Mengintrogasi.

3. Membuat perjanjian dalam bentuk tulisan/tertulis atau dalam bentuk lisan dengan cara memvidiokan perjanjian yang mereka ucapkan serta foto.

4. Menyelidiki rekam jejak di resor lain.

5. Melakukan pengarahan dan sosialisasi tentang aktifitas illegal dan tapal batas kawasan.

6. Melakukan penyitaan terhadap mesin/alat kerja lain.

7. Membawa pelaku dan barang bukti ke pihak berwenang (kepolisian).

Langkah dan tahapan tersebut berlaku untuk semua pelaku yang ditemukan dalam semua kasus pelanggaran kawasan dan pelanggaran keanekaaragaman hayati yang di temukan oleh tim. 
Pengimplementasian SMART Patrol yang dilakukan oleh resor Rundeng dari tahun 2016 hingga 2019 meunjukkan data penurunan jumlah kasus pembalakan. Data SMART Patrol menunjukkan bahwa temuan kasus pembalakan liar di resor Rundeng mengalami penurunan disetiap tahunnya. Penurunan jumlah aktivitas pembalakan liar tersebut pada tahun 2016 ditemukan banyaknya kasus pembalakan liar yaitu 446 kasus, tahun 2017 sebanyak 292 kasus, tahun 2018 sebanyak 147 kasus, dan pada tahun 2019 sebanyak 91 kasus.

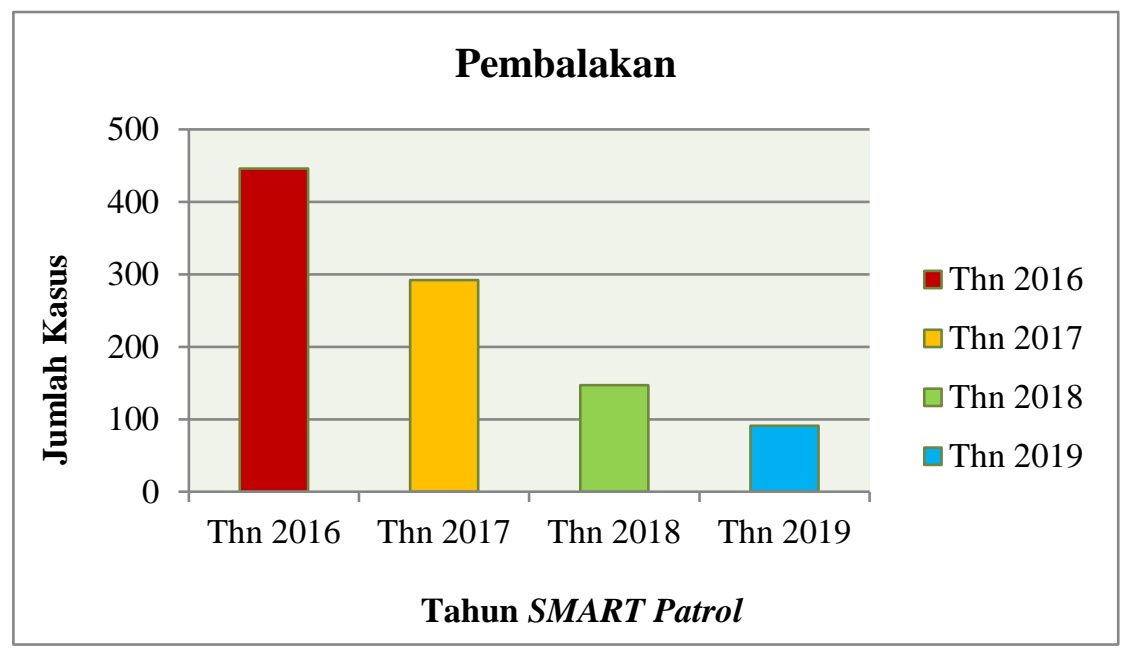

Gambar 1. Grafik Kasus Pembalakan Liar

Untuk terus menurunkan ancaman terhadap kerusakan kawasan habitat orangutan sumatera, slain rutin melakukan SMART Patrol pihak terkait juga selalu melakukan sosialisasi dan penyuluhan. Sosialisasi dilakukan bersama pihak kepolisian dengan tema "Stop Illegal Logging". Selain rutin melakukan SMART Patrol dan sosialisasi langsung dilapangan dengan para pelaku yang tertangkap, untuk mengurangi laju pembalakan di SM. Rawa Singkil, BKSDA Aceh bersama pihak kepolisian juga rutin melaksanakan sosialisasi. Sosialisasi dilakukan di desa-desa bersama masyarakat desa setempat terutama di desa yang berbatasan langsung dengan kawasan SM. Rawa Singkil.

Dalam sosialisasi ini pihak kepolisian sebagai pemangku wewenang hukum tindak pidana memberikan himbauan tegas kepada masyarakat agar tidak melakukan aktivitas yang dapat merusak kawasan hutan dengan cara menebang pepohonan hutan. Tema sosialisasi yang selalu digalakkan yakni "Stop Illegal Logging". Hal ini rutin dilakukan untuk memberikan pengertian kepada masyarakat tentang dampak-dampak yang akan terjadi jika kawasan hutan terus menerus ditebang dan mengalami kerusakan. Kegiatan itu akan menimbulkan dampak dan kerugian terhadap masyarakat itu sendiri. Salah satu dampak yang telah dirasakan oleh masyarakat sekarang salah satunya yaitu banjir. Pihak berwenang menjelaskan untuk tidak segan dan tidak ada pilih-pilih untuk menjatuhkan sanksi dan hukuman yang berlaku. Peraturan tentang larangan melakukan kegiatan pembalakan liar, pembakaran hutan dan perambahan kawasan hutan tertuang dalam UU No 41 tahun 1990 tentang Kehutanan pasal 50 ayat (3).

Melalui pendekatan ini, pihak berwajib juga ingin lebih mengenal dan lebih dekat dengan masyarakat di wilayah tugasnya. Hal tersebut dilakukan untuk melindungi semua pihak terutama masyarakat sekitar dari ancaman bahaya yang dapat ditimbulkan oleh 
kerusakan lahan gambut. Lahan gambut yang rusak akan menyebabkan kerentanan bencana pada lingkungan. Lahan gambut yang rusak akan menimbulkan bencana seperti kebakaran, dan banjir, dan hal ini merupakan ancaman besar bagi ketahanan wilayah (Asrofi, 2017). Ketahanan wilayah menurut Lemhannas (2000) yaitu kondisi dinamis yang meliputi seluruh aspek kehidupan masyarakat, dimana hal ini merupakan kemampuan masyarakat dalam menghadapaai dan mengatasi segala ancaman dan gangguan yang baik datang dari luar maupun dari dalam dan yang bersifat langsung maupun tidak langsung. Para pihak terkait beserta para mitranya terus berupaya melakukan segala kegiatan dan pendekatan untuk melindungi masyarakat dan lingkungan sekitar bagi masa sekarang dan masa yang akan datang.

Diharapkan masyarakat mampu mengerti dan bersedia secara bersama-sama untuk menjaga kawasan SM. Rawa Singkil beserta keanekaragaman hayati yang ada di dalamnya. Penerapan hukum dan sanksi juga diberlakukan terhadap pelaku kejahatan di kawasan tersebut.

\section{Perambahan}

SMART Patrol yang dilakukan pada periode Mei, Juni dan Juli 2019 di SM. Rawa Singkil juga mengamati aktivitas perambahan. Perambahan merupakan salah satu aktifitas yang diamati dalam parameter sebagai ancaman terhadap habitat orangutan sumatera. Namun, pada 3 bulan pengamatan di lapangan, tim tidak menemukan kasus perambahan tersebut. Baik di bulan Mei, Juni dan Juli 2019 kasus perambahan tidak ditemukan di dalam dan di luar kawasan SM. Rawa Singkil.

Resor Rundeng yang telah mengimplementasikan SMART Patrol sejak tahun 2016 hingga 2019 ini menunjukkan data yang positif. Data perambahan pada resor Rundeng pada tahun 2016 hingga 2019 mengalami penurunan yang signifikan. Kasus perambahan di SMART Patrol pada tahun 2016 menunjukkan data sebanyak 60 kasus, pada 2017 sebanyak 18 kasus, pada tahun 2018 sebanyak 10 kasus dan pada tahun 2019 hanya sebanyak 10 kasus. Grafik penurunan kasus perambahan tersedia pada gambar 2.

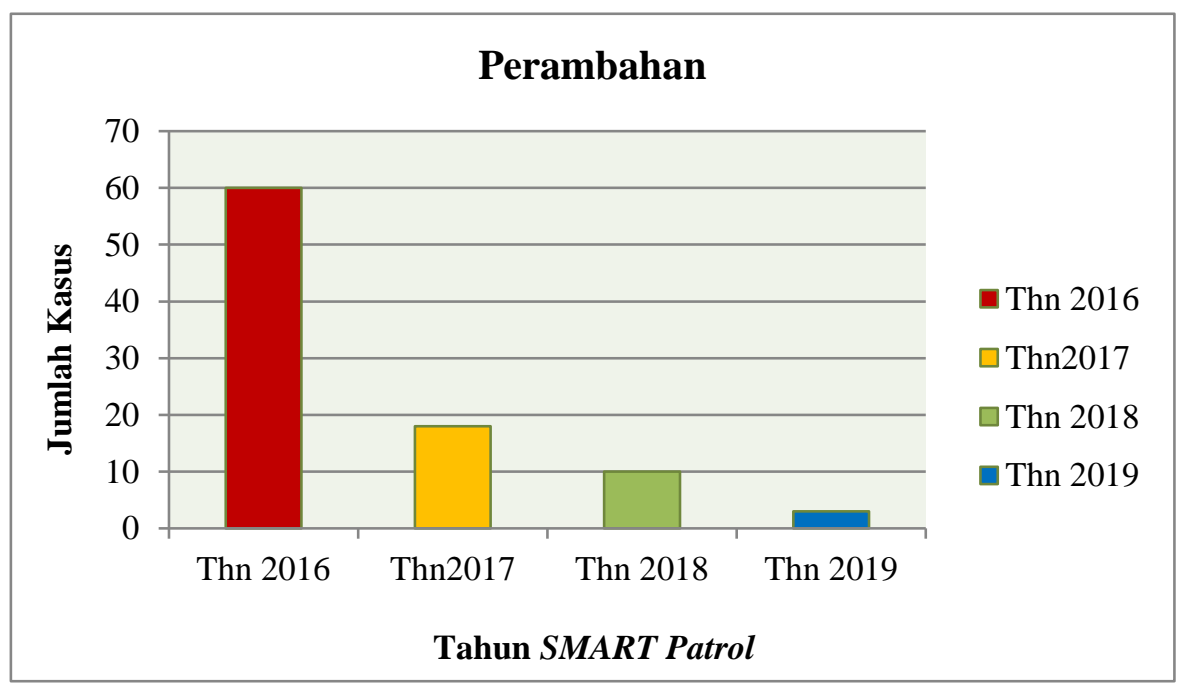

Gambar 2. Kasus Perambahan

Penurunan aktifitas dan temuan kasus tersebut tidak lepas dari SMART Patrol yang rutin dilakukan oleh resor Rundeng dari tahun 2016 hingga 2019. Selain kegiatan SMART 
Patrol yang dilakukan secara rutin, hal tersebut juga dibantu dengan menerapkan hukum dan sanksi serta adanya kegiatan sosialisasi yang dilakukan oleh pihak BKSDA, mitra, dan aparat kepolisian.

Perambahan kawasan hutan merupakan salah satu kegiatan penyebab penyempitan habitat orangutan sumatera. Habitat orangutan sumatra terus mengalami kerusakan dan penyusutan akibat kegiatan perambahan. Perambahan yang dilakukan adalah dengan mengubah kawasan hutan menjadi perkebunan dan pemukiman. Penurunan volume habitat tersebut menyebabkan orangutan kehilangan wilayah hidup dan wilayah jelajah yang menyebabkan terganggunya siklus kehidupan, hal ini menjadikan orangutan sumatera masuk ke dalam kategori sangat terancam punah (Dephut, 2007).

Perambahan hutan adalah suatu fenomena yang terjadi akibat interaksi negatif antara masyarakat dengan hutan. Interaksi tersebut merupakan interaksi yang timbul dari ketergantungan masyarakat terhadap kawasan hutan (Soetrisno, 1995). Selain interaksi yang salah dari manusia terhadap kawasaan hutan, perambahan juga disebabkan dari faktor latar belakang manusia. Beberapa faktor penyebab perambahan adalah dari faktor ekonomi, faktor sosial, kesempatan, penyalahgunaan wewenang, pendidikan masyarakat dan faktor politik (Alfanny et al., 2015).

Terlepas dari semua faktor yang ada, pihak terkait selalu berupaya untuk menumbuhkan kesadaran masyarakat agar tidak melakukan aktifitas negatif tersebut. Dengan terus melakukan sosialisasi, SMART Patrol dan penerapan sanksi hukum tersebut diharapkan dapat terus menekan penurunan kasus perambahan dan semua kasus yang dapat menimbulkan kerusakan terhadap kawasan SM. Rawa Singkil.

\section{Pengimplementasian Data SMART Patrol}

SMART Patrol yang dilakukan oleh pihak BKSDA Aceh SKW II Subulussalam bersama mitranya ini mempunyai fungsi bagi pengelolaan kawasan SM. Rawa Singkil. Seluruh data SMART Patrol dapat tersimpan dan digunakan sebagai data base bagi kawasan. Data base tersedia dari semua tim SMART Patrol baik dari tim resor Singkil, resor Rundeng dan tim resor Trumon. SMART Patrol yang telah dilakukan sejak tahun 2016 hingga 2019 ini telah memberikan dampak positif bagi kawasan baik secara langsung maupun tidak langsung.

Data SMART Patrol salah satunya telah digunakan oleh BKSDA Aceh untuk pembentukan dan penataan blok pada kawasan SM. Rawa Singkil. Pembentukan dan penentuan blok pada kawasan tersedia pada tabel 1. Hasil penentuan blok penataan tersebut bersumber dari data SMART Patrol yang telah didapat dari seluruh tim SMART Patrol. Berbagai informasi lain juga dapat tersedia dari data SMART Patrol seperti inventarisasi kawasan (HHBK/HHK), data tutupan lahan, sebaran satwa liar, serta informasi konflik tenurial.

Pada data base kawasan di SM. Rawa Singkil yang telah diimplemetasikan yaitu pada kasus tentang kejelasan kawasan lokasi kebun kelapa sawit antara masyarakat, perusahaan kelapa sawit Kota Subulussalam dengan Kabupaten Aceh Singkil dan pihak penerima kelapa sawit. Pihak BKSDA Aceh SKW II Subulussalam sebagai pemangku kawasan dan wewenang memberikan data-data kawasan. Semua data yang disajikan oleh pihak BKSDA Aceh SKW II Subulussalam tersebut bersumber dari data SMART Patrol. Segala informasi dan data yang di dapatkan oleh tim dari SMART Patrol sangat membantu dan berfungsi sebagai pengamanan dan pengelolaan kawasan SM. Rawa Singkil. 


\section{SIMPULAN DAN SARAN}

Kegiatan SMART Patrol dapat mendata segala aktifitas illegal dan potensi di lapangan. SMART menyimpan dan menyajikan data kawasan SM. Rawa Singkil. Parameter pada penelitian ini adalah ancaman terhadap habitat orangutan sumatera (pembalakan liar, perambahan, kebakaran) dan ancaman terhadap orangutan sumatera (jerat satwa, perburuan liar dan konflik antara manusia dengan orngutan sumatera). Selain itu, data SMART Patrol dapat digunakan sebagai data base untuk pengelolaan kawasan SM. Rawa Singkil. Pengimplementasian SMART Patrol yang dilakukan di lapangan serta kegiatan sosialisasi, penyuluhan, visit to school dan KSM dilakukan oleh pihak-pihak terkait yang bertujuan untuk pengamanan dan pengelolaan kawasan SM. Rawa Singkil beserta segala keanekaragaman hayati yang ada di dalamnya terutama orangutan sumatera. Kegiatan tersebut dilakukan dengan kerjasama dengan berbagai pihak termasuk menerapkan hukum dan sanksi.

Perlu dilakukan penelitian mengenai tingkat dan ragam ketergantungan masyarakat sekitar terhadap kawasan konservasi SM. Rawa Singkil. Perlu dilakukannya penelitian lanjutan mengenai tingkat pengetahuan masyarakat sekitar tentang kawasan SM. Rawa Singkil. Kegiatan SMART Patrol beserta semua komponen pendukungnya harus terus dilakukan agar benar-benar menyelamatkan kawasan SM. Rawa Singkil dari ancaman kerusakan dan ancaman terhadap seluruh keanekaragaman hayati yang ada di dalamnya.

\section{DAFTAR PUSTAKA}

Alfanny, Z., Markum., Setiawan, B. 2015. Analisis faktor-faktor penyebab perambahan hutan di kawasan Kecamatan Sambelia Kabupaten Lombik Timur. Program Studi Kehutnan. Universitas Mataram.

Asrofi, A 2017. Strategi Adaptasi Masyarakat Pesisir Dalam Penanganan Bencana Banjir Rob dan Implikasinya Terhadap Ketahanan Wilayah (Studi di Desa Bedono Kecamatan Sayung Kabupaten Demak Jawa Tengah). Jurnal Kehutanan Nasional. Vol.23, no 2 hh.125-144.

Departemen Kehutanan. 2007. Srtategi dan Rencana Aksi Konservasi Orangutan Indonesia 2007-2017. Direktorat Jenderal Perlindungan Hutan dan Konservasi Alam Departemen Kehutnan. Jakarta.

Lemhannas, 2000. Ketahanan Nasional. Jakarta : Balai Pustaka.

Puspita., R., O., 2015. Modul Aplikasi SMART (Spatialing Monitoring And Reporting Tools). Wildlife Conservation Society-IP Bogor.

Soetrisno, 1995. Menuju Masyarakat Partisipatif. Kanisius. Yogyakarta.

Rahmadi, R. 2019. Sisi Menawan Rawa Singkil yang Luput Perhatian. Tersedia https://www.mongabay.co.id/2019/02/10/sisi-menawa-rawa-singkil-yang-luputperhatian/amp/ Diakses Pada Tanggal 10 April 2019.

Wich, S. A., Singleton, I., Nowak, M. G., Atmoko, S. S. U., Nissam, G., Arif, S. M \& Gaveau, D. L., 2016. Land-cover changes prdict steep decline conservationfor the Sumatera orangutan (Pongo abelli). Science advances, 2 (3), e1500789. 